\title{
REFINED CONVEXITY AND SPECIAL CASES OF THE BLASCHKE-SANTALO INEQUALITY
}

\author{
D. Borwein, J. Borwein, G. FeE AND R. GIRGENSOHN
}

Abstract. We derive the $l_{p}$ version of the classical Blaschke-Santalo inequality for polar volumes as a consequence of more subtle convexity estimates for the volume of the $p$-ball in Euclidean space. We also give analogs for the $(p, q)$-substitution norm.

Mathematics subject classification (2000): 52A22, 26B25, 52A38, 33B15.

Key words and phrases: Psi function, Gamma function, modified convexity, volume of $p$-balls, substitution norm, Blaschke-Santalo inequality.

\section{REFERENCES}

[1] J. ACZÉL, The notion of mean values Norske Vid. Selsk. Forh., Trondhjem, 19, 83-86 (1947).

[2] G. ANDREws, R. Askey AND R. Roy, Special Functions, Cambridge University Press (1999).

[3] J. MATKOWSKI AND J. RäTZ, Convexity of power functions with respect to symmetric homogeneous means, Int. Ser. Numer. Math. 123, 231-247 (1997).

[4] J. MATKOWSKI AND J. RÄTZ, Convexity functions with respect to an arbitrary mean, Int. Ser. Numer. Math. 123, 249-258 (1997).

[5] G. PISIER, The Volume of Convex Bodies and Banach Space Geometry, Cambridge University Press (1989).

[6] L. Santalo, Integral Geometry and Geometric Probability, Addison Wesley (1984).

[7] D. V. WIDDER, The Laplace Transform, Princeton University Press (1941). 